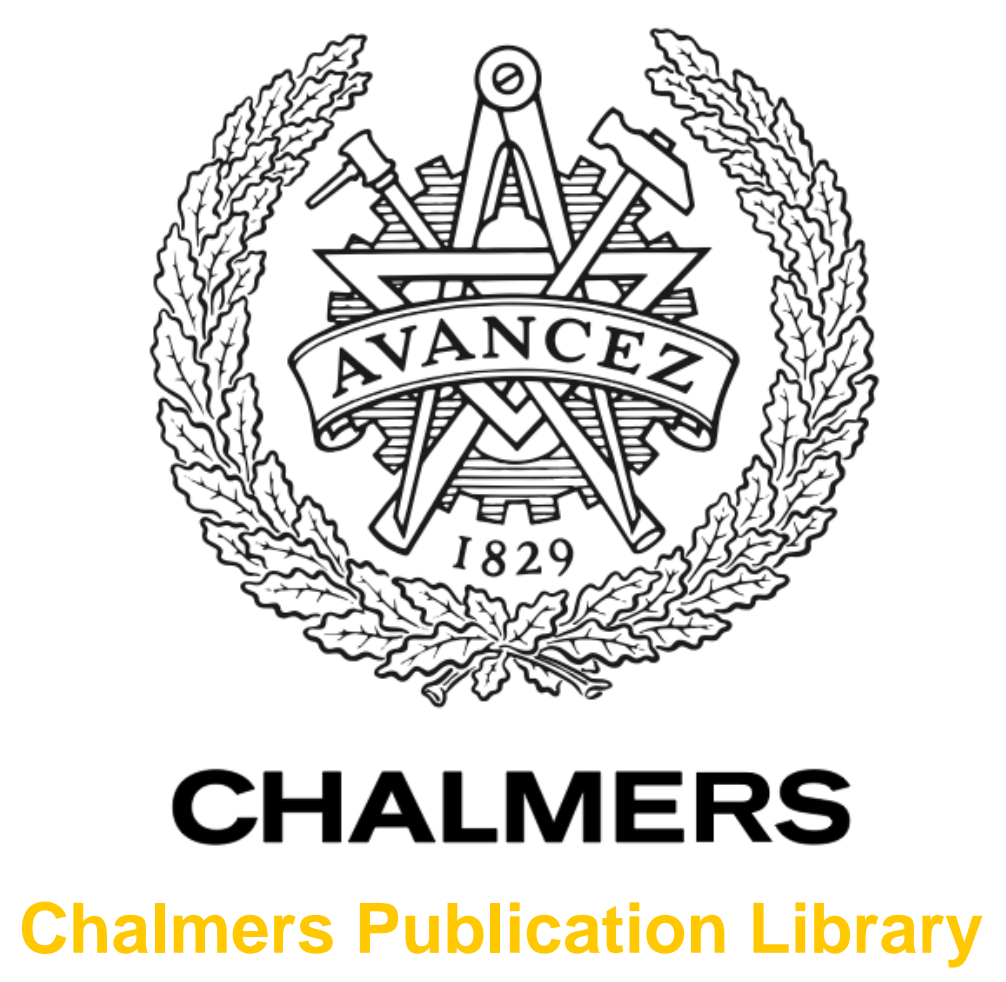

\title{
Introduction for special themed section: information and communication technologies and the work-life boundary
}

This document has been downloaded from Chalmers Publication Library (CPL). It is the author's version of a work that was accepted for publication in:

New technology, work and employment (ISSN: 0268-1072)

Citation for the published paper:

Hislop, D. ; Bosch-Sijtsema, P. ; Zimmermann, A. (2013) "Introduction for special themed section: information and communication technologies and the work-life boundary". New technology, work and employment, vol. 28(3), pp. 177-178.

http://dx.doi.org/10.1111/ntwe.12015

Downloaded from: http://publications.lib.chalmers.se/publication/186978

Notice: Changes introduced as a result of publishing processes such as copy-editing and formatting may not be reflected in this document. For a definitive version of this work, please refer to the published source. Please note that access to the published version might require a subscription. 


\section{Information and Communication Technologies and the Work-Life Boundary}

\section{Introduction for Special Themed Section}

Co-editors: Donald Hislop, Petra Bosch-Sijtsema, Angelika Zimmermann

The two papers published here emerged out of a subtheme that was organized at the 2012 European Group for Organization Studies (EGOS) Colloquium in Helsinki, Finland. The general aim of the subtheme was to contribute towards addressing gaps in the academic literature on the relationship between information and communication technology (ICT) use and the nature of the work-life boundary. We adopt a similar ontology to Orlikowski (2007) and Wajcman (2006) when examining work-related technology use. Thus, rather than assuming that technologies have intrinsic properties which determine their impacts, we assume that technological artefacts and social processes are mutually constitutive and inseparable. In examining the relationship between ICT use and the work-life boundary, the concern is thus not with the 'impacts' that ICTs have on this boundary, but how this boundary, and the domains of work and non-work are constructed through the active way people utilize various ICTs. The papers here therefore place a central focus on people's agency in shaping the way they use these technologies.

The importance of examining such issues is partly related to the growing academic interest in the topic of the work-life boundary that has emerged in recent years. However, it is also due to the growing extent to which technologies such as laptop computers, tablet computers and smartphones ${ }^{1}$ are being used as devices to both carry out work-related tasks, and to manage the work-life boundary. While obtaining accurate up-to-date statistics on the extent to which people are using these technologies for such purposes is challenging, anecdotal evidence suggests

${ }^{1}$ A smartphone is a generic label for mobile phones which not only provide call and text functionality, but also gives users access to mobile email and internet as well as other functionality such as calendaring and cameras. 
that such technologies are becoming ubiquitous work tools for a significant proportion of workers.

Research on the relationship between ICT use and the work-life boundary has already produced a number of insights. Firstly, work-related ICT use can create a sense of 'anytime, anywhere' contactability that may result in work increasingly encroaching into non-work time, and the work-life boundary becoming blurred and permeable (Orlikowski 2007, Sarker et al 2012). However, research by Wajcman et al (2008) contradicted these findings, and concluded that people had the ability to limit such impacts through the way they used their mobile phones. This links to a second key insight from relevant research, which is that the way people use these technologies to carry out work activities and manage the work-life boundary are highly diverse and also that they provide people with the means to manage the work-life boundary in ways which reflect their boundary preferences. See for example Golden \& Geisler's (2007) study of personal digital assistant use, and Matusik \& Mickel's (2012) study of smartphone use.

However, due both to the fact that research on this topic is relatively embryonic, and that the pace at which these technologies are developing is significant, many gaps in knowledge still remain. Firstly, much of the research has typically focussed narrowly on managerial and professional workers (Hislop \& Axtell 2011). This is a significant limitation as a heterogeneous range of workers makes use of these technologies in their work. Secondly, much of the research has concentrated largely on the way in which the demands of work impact on the non-work domain, neglecting to adequately account for how demands in the non-work domain impact on the work domain. The two papers published here add to knowledge on this topic in various ways. Firstly, they examine the experiences of neglected types of workers, with Sayah examining self-employed contractors in German's IT and media sectors, and Gold \& Mustafa examining self-employed home-based workers. Sayah's paper also highlights the complexity of the work-life boundary by acknowledging its twoway directionality, and its multiple dimensions. Finally, Gold \& Mustafa's paper 
highlights how people perceived a need to be constantly available to respond to client calls ('client colonisation') even though they used a range of different strategies to attempt to switch off from work.

Finally, thanks to everyone who participated in the EGOS subtheme, who submitted papers for consideration in this special issue, and who acted as reviewers for submitted papers (Axtell, Golden, Halford, Licoppe, Nansen, Panteli, Richardson, Tietze).

\section{References}

Golden, A, Geisler, C (2007). Work-Life Boundary and the Personal Digital Assistant. Human Relations, 60/3: 519-551.

Hislop D and Axtell, C (2011) Mobile Phones During Work and Non-Work Time: A Case Study of Mobile, Non-Managerial Workers. Information and Organization 21: 41-56.

Matusik, S, Mickel, A (2012). Embracing or Embattled by Converged Mobile Devices? Users' Experiences with a Contemporary Connectivity Technology'. Human Relations, 64/8: 10001-1018.

Orlikowski W (2007) Socio-Material Practices: Exploring Technology at Work. Organization Studies 28: 1435-1448.

Sarker, S, Xiao, X, Sarker, S, Ahuja, M (2012) Managing Employees' Use of Mobile Technologies to Minimize Work-Life Balance Impacts. MIS Quarterly Executive, 11/4: 143-157.

Wajcman, J (2006). 'New Connections: Social Studies of Science and Technology and Studies of Work'. Work, Employment and Society, 20/4: 773-786.

Wajcman, J, Bittman, M, and Brown, J (2008), Families Without Borders: Mobile Phones, Connectedness and Work-Home Divisions. Sociology, 42: 635-652. 
Donald Hislop (d.hislop@lboro.ac.uk) is a Reader in the Sociology of Contemporary Work Practices and Deputy Director of Professional Work and Society Research Centre in the School of Business and Economics at Loughborough University. One of his central research interests is into how the use of contemporary information and communication technologies is affecting the character and experience of work. He has published extensively in a wide range of business and management journals.

Petra Bosch-Sijtsema (petra.bosch@chalmers.se) is an associate professor at Chalmers University of Technology, Construction Management, Gothenburg, Sweden. She has a PhD in Management and Organization from Groningen University (NL). She has worked at universities in the Netherlands, Finland, Sweden and USA. Her research interests are in new ways of working, distributed and virtual work, knowledge work, ICT, innovation and knowledge creation and sharing, and collaboration within and between firms.

Dr. Angelika Zimmermann (a.zimmermann@lboro.ac.uk) is a Senior Lecturer in International Business \& Strategy in the School of Business and Economics, Loughborough University, UK. Her research focuses on international collaboration in global teams, offshoring arrangements, and expatriate assignments, with a special interest in the Indian, Chinese, German, and UK contexts. Her research has been published in the Information System Journal, International Journal of Human Resource Management, Journal of Vocational Behavior, International Journal of Management Reviews, International Studies of Management and Organization, and the International Journal of Cross Cultural Management. 